\title{
English language and philosophy
}

\author{
Jonathan Tallant ${ }^{\dagger} \quad$ James Andow $\ddagger$
}

\begin{abstract}
Philosophical enquiry stands to benefit from the inclusion of methods from the digital humanities to study language use. Empirical studies using the methods of the digital humanities have the potential to contribute to both conceptual analysis and intuition-based enquiry, two important approaches in contemporary philosophy. Empirical studies using the methods of the digital humanities can also provide valuable metaphilosophical insights into the nature of philosophical methods themselves. The use of methods from the digital humanities in philosophy should be expected to follow a similar trajectory to another attempt to introduce empirical methods in philosophy. Experimental philosophers use empirical methods from the cognitive sciences to bear on philosophical questions. At first, we should expect the main contribution of methods from the digital humanities in philosophy to be at the metaphilosophical level. Then, given the right impetus and support, we are optimistic that methods from the digital humanities can make important and sustained contributions to first-order philosophical enquiry. This chapter gives two case studies of recent studies in which methods from the digital humanities are used to address metaphilosophical questions about the use of the word 'intuition' and the methods of philosophy and physics. It gives three examples of contemporary first-order philosophical debates to which methods from the digital humanities could make an important contribution in epistemology, metaphysics and philosophy of language. The chapter discusses some methodological challenges and limitations which are of particular importance when considering the application of methods from the digital humanities in philosophy, including concerns about the demographic representativeness of widely available corpora.
\end{abstract}

*This is an author post-print. The chapter is published in The Routledge Handbook of English Language and Digital Humanities available here

tUniversity of Nottingham

‡University of East Anglia 


\section{Introduction}

There are many different views about the nature of philosophical enquiry. On many of these views, there is a significant philosophical contribution to be made by empirical enquiry into the ways that language is used in the real world by what we might call 'ordinary language users'. However, philosophers have rarely taken up the opportunity to study language systematically and empirically. The digital resources now available for studying language use in the corpus and other approaches in the digital humanities afford a real opportunity for philosophers to do just this.

This chapter addresses a number of questions. Why would evidence about language use be helpful for philosophers? What resistance might there be to this idea? How might this resistance be reflected in the ways that philosophers make use of corpus research and other approaches in the digital humanities? We begin with an overview of some of the ways in which philosophical enquiry has been carried out.

\section{Background}

In this section we outline two popular conceptions of philosophical enquiry and argue that those who conceive of philosophy in any of these ways ought to accept that systematic empirical enquiry into language use has an important contribution to make in philosophy.

Philosophers investigate a range of topics: morality, freedom, identity, existence, time, knowledge, gender and so on. When philosophers think about things like (for instance) freedom, and when they try to provide answers to questions like 'What is it to be free?' it seems important that what they mean by 'free' has got some connection with ordinary thought and talk about freedom. ${ }^{1}$ If the philosopher ends up talking about some completely new concept that isn't that of freedom, but is somewhat close to it (unimaginatively, let us call it 'schmeedom'), then there is a sense that the philosopher will have missed the point. We started off asking about freedom, and now the philosophers are off talking about something else - schmeedom (whatever that is and however, if at all, it is connected to the concept of freedom). If we wanted to know about what it is to be free, how that connects with morality, politics, science and so on, then talking about schmeedom just isn't going to help. With this background in mind, let's now explore some of the ways in which philosophical enquiry has proceeded.

\footnotetext{
${ }^{1}$ We'll employ the convention of using single quotes only when we want to say something about the words or expressions themselves.
} 


\subsection{Conceptual analysis}

Conceptual analysis is an attempt to analyse concepts. Concepts are, in the relevant sense, constituents of thought. To analyse them is to break them down, to understand their structure in more basic terms. The idea that conceptual analysis is central to philosophical enquiry can be traced back to Socrates (Beaney 2015).

One oft-discussed example is the (flawed) analysis of knowledge as justified, true belief. The idea was that the concept of knowledge might be analysed in terms of the more basic concepts of justification, belief and truth. Were the analysis correct, then we could correctly say that a subject, $S$, knows that $\mathrm{p}$, if and only if, $\mathrm{S}$ has a justified true belief that $\mathrm{p}$.

One traditional assumption was that a philosophical analysis of a concept would produce something like a definition, providing a set of necessary and sufficient conditions. Providing something like a definition is, however, just one example of how one might attempt to analyse a concept in terms of something more basic. Following psychologically informed criticism, philosophers have become more open to the idea that the result of analysing a concept might be something other than a definition, for example, the concept might take the form of a prototype, exemplar or theory (see Laurence and Margolis 1999). ${ }^{2}$ It is important to register that even among proponents of conceptual analysis, there are different views about where the project of conceptual analysis should get you (Goldman 2007). Some take the endpoint to be an articulation of the concept of one's linguistic community, whereas others take the endpoint to concern a universally shared concept, or to reveal the nature of the relevant phenomenon itself (e.g. knowledge, via revealing the concept of knowledge).

Now we said earlier that there was a close tie between language use and philosophical methodology. So, what's the connection between analysing concepts and language use? Philosophers will have various opinions about this. We're going to play safe and simply set aside two extreme, implausible positions.

(1) Language use and concepts have nothing to do with each other.

It might seem simply obvious that this is an implausible position. However, it is worth articulating why.

Language expresses thoughts, and concepts are constituents of thoughts. It would therefore be very strange if language in no way reflected the nature of our concepts. For instance, if a philosopher's analysis of a concept bore no resemblance to the way anyone ever used the word 'knowledge' then it wouldn't be an analysis of the concept of knowledge. The analysis would have failed.

If that's right, then there should be scope for systematic empirical investigation into real language use to provide evidence which can inform the project of analysis.

${ }^{2}$ For a recent, psychologically informed account of how conceptual analysis might work, see Machery (2017). 
This said, it is also important for us to note that (2) is also completely implausible. ${ }^{3}$

(2) A community's concept of knowledge can be simply 'read off' their use of certain words.

To illustrate the problem with this approach, let us use an example. This understanding of the relation between words and language is committed to the idea that when a community apply the word 'fish' to something this is to be interpreted as a correct application of their concept. But that's implausible, and wouldn't permit a community to discover that, after all, they'd been wrong to think the concept of fish extended to whales. We cannot simply 'read off' which applications of a concept are correct from the use of language within a community. It is perfectly possible for communities to just get it wrong. Whatever the relation between language production and conceptual content, it is not as straightforward as (2) would suggest.

Our claim, then, is that there is scope for corpus research, and other lines of research within the digital humanities, to discover previously unknown facts about the factors and associations that, for example, underpin people's use of (for instance) 'knows'. For example, were a close analysis of a corpus to reveal the widespread phenomena that competent language users were prepared to assign knowledge to an agent, even in a variety of contexts where that agent has no justification for their belief, then that would have served to put pressure on the claim that we can analyse the concept of knowledge as the concept of justified true belief.

In pursuing this line, we advocate a position that we think is taken by Rosenbloom (2012). We are not opposed to philosophical methodology as it has been practised. We recognise that it has value and that it helps us to gather insight. Nonetheless, one way to consider the scope of the digital humanities in general is as of giving us additional methodological tools with which to approach old questions (as well, of course, as providing us with more questions to ask - more of which at the end of the chapter). Our general approach to philosophy, as incorporated within the digital humanities is largely summarised thus:

The scientific method provides a validated approach for developing insights, but it is not the only method, nor necessarily always the most appropriate method. For any particular domain, and any particular problem within that domain, there may be zero, one, or more methods applicable to them. If we define the strength of a method for a domain or problem as the degree of veracity it can guarantee for the results it generates, good science should in general be pursued via one from among the strongest applicable methods. Using

\footnotetext{
${ }^{3}$ Although, naturally, were you to think that, then you would need little persuasion of the main claims in this chapter.
} 
weaker methods when stronger ones are available can be one of the hallmarks of bad science. We need to be careful, though, about what is meant by two methods being applicable to the same problem, and thus the circumstances under which a stronger method should necessarily dominate. If two methods can yield the same insights and one provides more assurance with respect to these insights, then the two are applicable to the same problem and the stronger should be preferred. However, if the problems are nominally the same but the two methods provide different insights about it, then the weaker method may still be of value, and the problems they tackle are in an important sense different.

The potential diversity of appropriate methods, both within and across domains, does suggest a form of methodological pluralism in which multiple methods may be necessary to increase our understanding of individual domains (Rosenbloom 2012: 7-8).

Not every philosophical question is well treated by the more scientifically oriented aspects of the digital humanities. That's fine. Nonetheless, the methods that we can draw upon - as we shall show in a moment - do allow us to generate additional insight and give us more data with which to approach long-standing problems. Our primary aim in this chapter is to demonstrate that this is so and to make the case for the inclusion of methodologies from the digital humanities within philosophical enquiry.

\subsection{Intuition-based enquiry}

Many contemporary conceptions of philosophical enquiry give an important role to something they call 'intuitions'. Philosophers variously treat intuitions as data, as infallible evidence, as defeasible or pro tanto evidence, as inspiration and so on. We shall group all these under one heading. What justifies treating all these approaches under one banner is that they all in some sense treat philosophical enquiry to be limited or guided by what is congruent with our intuitive judgements about philosophically interesting things - knowledge, morality, freedom and so on. ${ }^{4}$ The motivation for this way of approaching philosophy can be somewhat similar: if a philosopher's account of justice were to be completely divorced from our intuitive ways of thinking about justice, it would be unclear what made the account an account of justice rather than something else.

What is an intuition? Here, again, we encounter a variety of opinion. We can't hope to do justice to all of them. ${ }^{5}$ We think we can say, however, that most have in mind something like a fairly quick, non-inferential, pre-theoretic judgement about whether something applies. Sometimes a reliance upon intuitions is cast explicitly in linguistic terms - 'intuitively,

\footnotetext{
${ }^{4}$ Some ways of cashing out the project of conceptual analysis also give an important role to intuitions. But we'll treat the two separately here.

${ }^{5}$ For a brief introduction to some of them, see Jenkins (2014), Pust (2014) and Cappelen (2012).
} 
we wouldn't say that such a person was free' - but often it is not. A fairly typical idea might be that if a theoretical position entails a picture of the world which runs completely counter to our intuitive way of thinking, then this counts against the theory in some way. Given the audience of this chapter, we should probably mention Chomsky. Some philosophers have drawn connections between philosopher's use of 'intuition' and that in linguistics postChomsky Hintikka 1999). However, Chomsky's philosophical inspirations notwithstanding, in the majority of cases, contemporary philosophers' use of 'intuition' does not indicate anything like judgements of grammaticality, nor reflect a belief in a special faculty of intuition analogous to a universal grammar. In many cases, philosophers' use of 'intuition' doesn't indicate any strong commitment to a distinctly a priori mode of enquiry.

There's no straightforward consensus concerning the connection between intuition use and language use. However, we're inclined to endorse a similar line of reasoning to that considered earlier when talking about conceptual analysis: the idea that what people say can provide no insight into their intuitive ways of thinking about the world is pretty farfetched. If ordinary intuitive ways of looking at the world are thought to place limitations on which philosophical theories are plausible, or provide evidential support for or against theories, then it looks like corpus linguistics can have a hand to play. For, of course, what corpus linguistics can do for us is to reveal precisely the contexts in which people assert various different claims and so, on the assumption that people do not typically make widespread use of turns of phrase that are 'counterintuitive' corpus linguistics can give us some insight into their intuitions about whether particular uses of a term are 'intuitive' or not.

\section{Current contributions and research}

To remind the reader: our aim here is to make the case that philosophy has something to gain from broadening its scope and including particular methodologies from the wider digital humanities. To show that this is the case, we want to consider two particular cases. Methodologically we are looking to show particular cases where digital methods have provided value and then look to generalise from these cases.

The two case studies we consider here concern papers which we wrote (although not together). Of course, we are neither the first to suggest that the philosophical enquiry might benefit from looking at language use in a systematic way nor the first to put such recommendations into practice (the Oslo school did both - see e.g. Naess 1938). However, these two cases studies help make clear a number of points that we want to bring out and that demonstrate the further insight that the digital humanities can bring to philosophical questions. The first is to help make clear the contribution that both quantitative and qualitative approaches to looking at usage can make to philosophical debate. The second is to demonstrate that examination of language usage, in addition to helping those engaged in 
conceptual analysis or intuition-using philosophy, can help advance our understanding of philosophical methods themselves - this metaphilosophical theme is one we'll pick up again later.

\subsection{Exploding intuitions}

Andow (2015b) examines an aspect of current debate about the methods philosophers use. A number of high-profile commentaries on the philosophical methods have noted that philosophers use the word 'intuition' a lot more than they used to. Andow presents a quantitative study to investigate this phenomenon - to see what might underpin this change, and indeed to confirm whether there has been a change.

Andow uses JSTOR as a corpus of academic writing. Unlike other available bodies of text, JSTOR allows for fine-grained diachronic study, as articles are tagged by publication year. JSTOR also allows for a comparison of academic disciplines, as articles are tagged by subject areas. Andow was able to track the proportion of articles in each discipline by decade which made use of one or more of the following terms 'intuit', 'intuition', 'intuitive', 'intuitions', 'counter-intuitive', 'intuitively' and 'counter-intuitively'. The headline finding was that, surprisingly, while the proportion of philosophy articles mentioning at least one of these words has risen dramatically, the same has happened across a broad swathe of academia.

The import of this finding is that whatever does underpin the explosion of 'intuition' in philosophy it is likely not to be something philosophy specific. Indeed, Andow also reports data from the Time Magazine corpus and Google Ngrams (fiction) which suggest that the frequency of 'intuition' has risen more generally. This means that any metaphilosophical conclusions one might have been tempted to reach on the basis of noting the increase in use of 'intuition', for example, that there has been an increase in the use of intuition, seem not to be warranted.

\subsection{Intuitions in physics}

This second case study also concerns intuitions and philosophical methodology. Tallant uses the results of a qualitative analysis of the use of the word 'intuition' in physics (Tallant 2013) to make an important point about methods in an area of philosophy called metaphysics (Tallant 2015). ${ }^{6}$

Tallant aims to offer some resistance to those who claim metaphysics is not in good epistemic standing on the basis that metaphysicians use intuitions. Tallant is interested in

\footnotetext{
${ }^{6}$ Tallant also draws on an ethnographic study by Marton et al. (1992) of interview data from Nobel laureates and survey data from a study by Martinson et al. (2005) concerning scientists' use of 'gut feelings'.
} 
giving a kind of parity defence: physics uses intuitions, too, and there is no doubting the success of physics, so we shouldn't think metaphysics so badly off just because it uses intuitions. Tallant's opponents don't accept this parity. Ladyman and Ross (2007), for instance, claim there are important differences between what is going on when a metaphysician uses the word 'intuition' and when a scientist uses the word.

It is frequently said of, for example, a good physicist that he or she has sound physical intuition... However, the meaning of 'intuitions' in these uses differs sharply from the metaphysician's. The physicist ... [refers] to the experienced practitioner's trained ability to see at a glance how their abstract theoretical structure probably - in advance of essential careful checking - maps onto a problem space. (p. 15)

Tallant notes that this move requires an empirical claim for which Ladyman and Ross present no evidence. Tallant uses his own recent empirical work (2013) to challenge Ladyman and Ross's assumptions about use of 'intuition' in physics.

Tallant (2013) makes use of a number of techniques. First, like Andow (2015b), earlier, Tallant presents the basic proportions of articles in a number of top physics journals (Physical Review Letters, Review of Modern Physics, Physical Review AE, Physical Review Special Topics Energy Beams) between 2001 and 2010 which use 'intuitive' (including 'intuition' and 'counter-intuitive'). It is around 9 percent. However, Tallant goes beyond these crude numbers and provides some qualitative assessment. Second, Tallant presents a basic thematic analysis of the uses of 'intuitive' in this corpus based on a small subset of articles. Third, Tallant also presents findings relating to one journal in particular (The Review of Modern Physics) relating the number of uses of 'intuitive' which fall under each theme. Building on this, Tallant (2015) has analysed the data concerning the use of intuitions in physics and the use of intuitions in metaphysics and argued that it is not at all clear that the arguments against metaphysics go through. ${ }^{7}$

\section{Future directions}

Whether one thinks looking at the corpus is a worthwhile activity for a philosopher depends on how one thinks of philosophical enquiry. Earlier, we noted some conceptions of philosophical enquiry which could be quite friendly to this sort of research. However, it is worth noting that these conceptions are themselves not uncontroversial.

\footnotetext{
${ }^{7}$ Again, there are subtleties to this debate, and Tallant $(2013,2015)$ offers only a partial defence. Please turn to the original papers for the full story. This brief account suffices for our purpose here.
} 
One helpful way to make this point is to consider the case of experimental philosophy. Experimental philosophy is a relative newcomer on the philosophical scene. It is around 15 years old at the time of writing. The main characterising feature of experimental philosophy is the idea that systematic empirical investigation into how people think about philosophically interesting things, like freedom, morality and the rest, can help advance philosophical debate about those things (Knobe and Nichols 2008). To that end, experimental philosophers advocate the use of experimental methods from social psychology, and the cognitive sciences more broadly. ${ }^{8}$ Experimental philosophers motivate their use of these methods by appealing to precisely the same kind of considerations that we have given to motivate systematic empirical study of language use. Experimental philosophers too have appealed to popular conceptions of philosophical enquiry such as conceptual analysis and intuition-using philosophy (See Knobe and Nichols 2008). ${ }^{9}$

The lesson we can learn from this concerns the resistance experimental philosophers have faced from some other philosophers (e.g. Cappelen 2012, 2014; Deutsch 2010; Kauppinen 2007). One of the responses that experimental philosophers face is that their work is fundamentally misconceived - that the kind of data they were collecting, for example, what ordinary people think about morality, is irrelevant to what the correct moral theory might be. This response relies upon the idea that conceptions of philosophical enquiry as being conceptual analysis or using intuition are mistaken - or at least that the ways of understanding these projects such that they are amenable to empirical enquiry of the kind advocated by experimental philosophers are mistaken.

Accordingly, advocates of corpus-based methods in philosophy should be prepared for similar resistance. We'll return to this thought shortly. First, however, it is interesting to consider a respect in which this resistance shaped the trajectory of experimental philosophy. This relates to the point we made earlier about the contribution made by our two case studies being predominantly metaphilosophical.

A dominant trend in early experimental philosophy was it was not involved in 'firstorder' philosophy, for example, using experiments to inform philosophical theorising about morality, but rather in metaphilosophy. A number of much-discussed papers were published that tried to challenge common metaphilosophical assumptions: for example, to make the case that philosophers couldn't safely assume that their intuitions were reliable or that

\footnotetext{
${ }^{8}$ There is room for debate about how exactly to characterise experimental philosophy. Some have advocated conceptions broad enough such that the approaches we are advocating here would snuggle in under the umbrella. We are inclined to think there is reason to keep empirical approaches focused on language use separate, however.
}

${ }^{9}$ Although, one of us has argued that this is problematic (Andow 2016). 
their intuitions were representative of the population at large. ${ }^{10}$ This early metaphilosophical flavour to experimental philosophy should, in some respects, not be too surprising given the nature of the resistance experimental philosophy faced. Metaphilosophical work faced less resistance at least in the sense that it was far less easy for philosophers to dismiss the work as irrelevant - the conclusions might be wrong but not irrelevant - these metaphilosophical experimental studies raised direct challenges to standard philosophical practice and, even if philosophers thought the challenges were mistaken, it was recognised that these studies needed to be discussed. It is thus then not so surprising that there is a metaphilosophical flavour to our two case studies. ${ }^{11}$

Andow $(2015 b)$ and Tallant $(2013,2015)$ also share another feature in common with early work in experimental philosophy. ${ }^{12}$ Another type of study which was prominent in the early days of experimental philosophy was that which picks up on empirical claims made in the philosophical literature. Sometimes these were explicit claims which clearly played the role of premises in an argument (e.g. Nichols et al. 2003). This is what Tallant (2015) did - picking up on Ladyman and Ross's claim concerning the role of intuition in science. Other times, the relevant empirical claims were not necessarily used as premises in any explicit argument, but nonetheless betrayed a particular underlying understanding of some particular phenomenon (see, e.g. Stich and Weinberg 2001; Knobe 2007's description of the inspiration for the now-rich literature on whether non-philosophers are compatibilists). This is what Andow did - challenging the idea that the major factor underlying philosophers' use of the word 'intuition' are philosophy-specific factors. These sorts of cases encounter less resistance because the relevance of the empirical work to the philosophical debate is simply obvious: when philosophers make empirical assumptions, these are open to empirical challenge.

\footnotetext{
${ }^{10}$ In fact, more generally, one of the major influences of experimental philosophy has been to lead philosophers to think carefully about their methodological assumptions. For example, various parties have come out in force articulating conceptions of intuition-using philosophy which do not rely on assumptions that philosophers' intuitions would be representative of some wider population (e.g. Williamson 2007). One of the latest trends is to argue that while it might look like philosophers use intuitions as evidence, in fact they don't do anything of the kind (Deutsch 2015; Cappelen 2012).

${ }^{11}$ This early trend in experimental philosophy has not persisted. This kind of metaphilosophical work has now largely given way to other projects. Only 1.1 percent of experimental philosophy papers published in the period 2009-2013 were of this kind (Knobe 2016).

${ }^{12}$ This feature is also shared by an example of research in the history of philosophy that uses the tools of corpus research. Edward Slingerland and colleagues use corpus tools to evaluate empirical claims about a historical philosophical corpus (e.g. Slingerland 2013; Slingerland and Chudek 2011; Slingerland et al 2017). They use quantitative tools to reanalyse the corpus of ancient Chinese philosophy to challenge a standard narrative that the idea of mind-body dualism is absent in ancient Chinese philosophy (and perhaps peculiar to Western philosophy).
} 
The lessons to take from all this is that we should not expect philosophers to start pursuing conceptual analysis using serious corpus research overnight. We should expect similar resistance to the employment of methods from corpus linguistics. But the parallel with experimental philosophy also gives a source of hope. Experimental philosophy has flourished. Further, it has not confined itself to metaphilosophical contributions and testing philosophers' empirical claims. The bulk of current work in experimental philosophy is engaged in a serious attempt to understand how people think about philosophically interesting things. So, we think there is reason to think that - given the right impetus and support - the use of systematic empirical study of actual language use will also be able to flourish and develop serious empirical programmes investigating how people talk about philosophically interesting things. ${ }^{13}$

\section{Critical issues}

It is well and good for us to argue that there is scope for these tools to be used. There will be issues faced along the way. We wish to discuss some of these here in the interests of trying to argue further in favour of their uptake.

The proponent of use of methods from corpus linguistics (and the digital humanities more generally) in philosophy should be encouraged by the fate of experimental philosophy. We must also keep in mind certain facts from the recent history of philosophy. One school of thought in philosophy, prevalent in the early-to-mid twentieth century, focused almost exclusively on language use. This school, called ordinary language philosophy, treated the sole task of philosophy as reflecting on linguistic practice. In part for reasons we give earlier, and in part for other reasons, this approach to philosophical enquiry has become markedly less popular in recent years. Philosophers tend to see the words that we use as a guide to how we think reality is (and given the fact that these thoughts appear in successful scientific theories about the world, how the world itself is), but their focus extends beyond the words and into the world itself. We would be sensitive, then, to any criticism that what we are extolling here is an approach to philosophy that just focuses on the way that people use words. We take the view that the approach that we are arguing in favour of here is one that incorporates the linguistic data available via (e.g.) corpus linguistics and applies them in a range of different cases. To illustrate, we provide to cases that we think are ripe for exploration via corpus linguistics or other methods that might all fall under the remit of the digital humanities.

\footnotetext{
${ }^{13}$ One space to watch is the work of Alfano and colleagues. In recent articles, they make the case for greater use of data mining and data visualisation in philosophy (Alfano and Higgins 2019) and put it into practice (Alfano et al. 2018).
} 
The first case is drawn from epistemology. Within epistemology, there are longstanding problems. In particular, there is a question about whether or not knowledge is possible. It seems obvious that it is, of course. For example, you know that you're reading this chapter. But things are not so straightforward. For it seems at least possible that you're wrong about that. Isn't it possible (in the most expansive sense of the word 'possible') that you're being deceived? Might you not be installed in some vat - à la The Matrix? It seems you can't rule out the possibility and if you can't rule out the possibility of being a brain in a vat, then it seems false to say that you know that you are reading this chapter.

One popular recent response has been to argue that this is an example of the standards for the term 'knows' applying varying from context to context (for an overview see Rysiew 2011). In normal contexts, it seems obviously correct to say that you know that you are reading the paper. But once we introduce some sceptical possibilities, we 'raise the standards' required for knowledge. The idea, very roughly, is that the term 'knows' functions similarly to the term 'tall': the term tall can be truthfully applied to Jack in some contexts (when Jack is visiting his daughter's primary school class), but it can also be truthfully said of Jack in other contexts that he is 'not tall' (for instance, if he is visiting an NBA team).

We do not propose to delve into the debates about the term 'knows' or to involve ourselves in the intricacies of the different positions available, but we do note that all parties in this debate appeal to linguistic data. It is common enough to see philosophers in this literature claim that within a particularly stylised context, the correct use of a particular term is $\mathrm{x}$, where $\mathrm{x}$ then supports their theory or undermines the theory of their opponent. ${ }^{14}$ Where we think that corpus linguistics may get some traction, then, is in determining whether there are such cases 'in the wild' and whether the terms being discussed are used as the philosophers claim. We might, thus, move the literature beyond philosophers swapping their linguistic intuitions, and deploy large datasets to determine which usages really are viewed as apt. ${ }^{15}$

Our second case is drawn from metaphysics - in particular, the metaphysics of time. One semi-popular view in this literature is presentism - the view that only present objects exist. This view, presentism, is often motivated by the claim that it is particularly intuitive; that it is the view of the 'person on the street' and is particularly commonsensical. To the best of our knowledge, these claims have never been verified. One way to test these claims would be via interviews or surveys - the latter are used regularly enough in the experimental philosophy that we described earlier; interestingly we know of no one using interviews.

\footnotetext{
${ }^{14}$ Indeed, Hansen (2014) construes this debate as a contemporary form of ordinary language philosophy.

${ }^{15}$ This is a particularly promising area because it is somewhat common for epistemologists to recognise the potential import of data from the corpus and to make some limited use of this (e.g. Nagel 2013, n.22), and there is already a big experimental philosophy literature in this area (see Buckwalter 2012 for a survey).
} 
Another way in which to test these claims would be via corpus study. For, presumably, if presentism really is the most intuitive view of time, and really is the common-sense view of the 'person on the street', then we should expect to see that reflected in their use of language. Very crudely: we might expect to see past objects described as 'non-existent'; we might expect to see future objects described in such a way as to imply their non-existence. And were we to not find that, it might well put some pressure on the claim that presentism is especially intuitive, or really is the common-sense view of the person on the street.

Our third and final case is drawn from the branch of philosophy that explores propositions. Very roughly a proposition is thought to be that which is expressed by sentences - the meaning of what is said and thought, if you will. (Thus, two sentences in different languages can be used to express the one and the same proposition; the two sentences can have the same meaning.) One debate about the nature of propositions concerns whether different tokens of the same type of sentence, uttered at different times, express different propositions, or whether they express the same proposition - though a proposition that can change with respect to whether it is true or false. Consider the sentence:

(1) Nixon is president

On a temporalist reading, what is expressed by (1) may change its truth-value over time: once it was true, now it is not. Nonetheless, there is but one proposition expressed by (1) at the two times under consideration, and it changes its truth-value. In contrast, on an eternalist reading, the proposition expressed by (1) does not change over time. Rather, at different times the same sentence can be used to express different propositions. Very crudely, we might think that something like the following is going on if eternalism is true. Uttered in 1970, (1) expressed a proposition that had the form: at 1970, Nixon is president. Uttered in 2016, (1) expresses the proposition that has the form: at 2016, Nixon is president. It is clear enough that the latter is false and that the former is true. However, such propositions are, if true at all, eternally true. The proposition at 1970, Nixon is president is true now, it was true in 1970 and it will be true in a thousand years' time.

One recent piece of work on this topic, due to Mark Richard (2015) explores this issue by considering a range of possible assertions, using these as evidence to favour one of these two views. Throughout the book, where he deals with a range of different issues, Richard draws on the ways that, he thinks, people will think about and respond to the cases that he considers (2015: 116 is especially vivid). In his own terms, here is Richard describing his methodology: 2015: 3 - our italics):

the argument is resolutely empirical: if we look at the way that we talk about belief, assertion, and so on, we find it poorly understood in terms of transiently true propositions.

Now, be that as it may, Richard does not engage in any of the tools that the digital humanities might provide us with: he does not deploy corpus linguistics, he does not use 
surveys, he does not interview respondents. In other words, there are a number of tools that would help us to look at the way that we talk about belief, assertion and so on, and these are not being exploited. He is not alone in this field. We think that Richard's work is very powerful, as is the work of others in this field, but it may be that augmenting it with the resources from the digital humanities would render it even more so (see Tallant (forthcoming) for further discussion).

\subsection{Mastering corpus research methods for use in philosophy}

Here again we can learn lessons from the fate of experimental philosophy. The general narrative told about experimental philosophy is that it has grown to be very empirically sophisticated and expert from rather less sophisticated and expert beginnings. There are various reasons for this. Early experimental philosophers didn't have an extensive grounding in statistics or survey design. They had to learn on the job. They were creating research traditions and had to develop new experimental paradigms. They had to develop new tools to look at philosophically interesting issues which the psychological literature didn't address. Similar issues will face proponent of empirical investigation of language-use in philosophy. For example, we definitely recognise (1) that our corpus case studies discussed earlier have their limitations and (2) that the fact we were newcomers to corpus-based work and we were asking new types of questions held us back in certain regards.

There was no pre-existing corpus structured in such a way that would allow one to address the questions Andow (2015b) addresses and the skills needed to develop the necessary corpus are far beyond a philosophers' usual skillset. While Andow was able to be creative utilising JSTOR - this means the study has important limitations, e.g. an inability to look closer at different uses (as one can't look within articles except by manually checking some sample of those to which the researcher has institutional access), and a lack of frequency data. ${ }^{16}$

The study carried out by Tallant also had certain limitations. As noted earlier, the approach that Tallant took was to search for instances of the words 'intuition' and 'intuitive' in a range of scientific literature. But this approach is, we suggest, rather simplistic. For instance, the approach that Tallant (2013) takes ignores the issue of whether or not these instances of terms are in fact referring to a use of intuition or whether they appear as (for instance) something like a verbal tic (see Cappelen 2012). Thus, on the basis of this evidence Tallant (2013) fails to establish (though admittedly does not take to have established)

\footnotetext{
${ }^{16}$ In fact, Andow (2015b) did suggest several potential explanations of his results, and he did follow up this study with a qualitative study of intuition talk across contemporary academic use (Andow 2015a). However, due to a lack of familiarity with applied linguistics, one potential explanation was overlooked. This, and its metaphilosophical implications, are now explored in Andow (2017).
} 
that intuitions really are being used in physics (though Tallant (2015) is more definite in this regard).

Similarly, Tallant fails to track whether or not other terms in the scientific literature might stand proxy for 'intuition' in particular contexts. We note, here, that there is discussion in the philosophical literature as to whether or not apparent cognates of 'intuitive' like 'it seems common sense' and 'it seems right to suggest' really do all refer to intuition. But as will be familiar to those with a background in corpus linguistics, the norm when engaging in a study such as Tallant's (2013) is to generate a 'coding manual' that allows the researcher to look for a particular term and its cognates, thus identifying cases where intuition (or another concept) is being referred to, but in an indirect fashion. All such uses were missed by Tallant (2013). As alluded to earlier, philosophers are interested in whether particular concepts or ideas are being used, and are not interested in cases where words are used with alternatice meanings, or cases where, as just suggested, a term might not be referring to a particular concept, but might simply be a product of a particular fashion of writing. It is therefore pressing that philosophers employing the methods from corpus linguistics do so with an appropriate respect for the methodology required by the linguistic approach.

Here another lesson can be learned from experimental philosophy. Experimental philosophy really came into its own through genuine collaboration between philosophers and psychologists, and through the interest and enthusiasm of graduate students whose dissertation projects included empirical elements. For these things, you need the right supportive environment. This includes things like willingness to work collaboratively across disciplinary boundaries, willingness to co-supervise $\mathrm{PhD}$ students outside one's own area and an openness and receptiveness to new methodological approaches. One might then expect the value of corpus linguistics to philosophy to become evident only once the project is properly up and running.

In general, though, these teething issues are to be expected. Though tools and methods from the digital humanities have not fully broken through into philosophy as yet, they have begun to do so in other disciplines. In her discussion of the development of these methods, Terras (2016: 1641) notes that:

the most difficult, intellectual work of applying technology in the humanities still occurs before the chasm has been crossed, in the phase of innovation, and early adoption, where we are looking at the technologies that cross our path and saying 'how can I use, or develop this tool for use, in my research?', much like those in the 1950s or 1960s who were coming across university mainframes and asking how best to apply that in the literary and linguistic arena.

And though we take ourselves to be making the case for particular uses of these methods within philosophy, it's clear enough that more work will need to be done. But - and this really is our point here - that work has not yet really been done. In the absence of clear and 
well-developed discussions in the wider philosophical literature as to how these different methodologies can be deployed, it's unsurprising that there is not yet a significant body of heavily digitally driven philosophical research.

\subsection{Worries about chauvinism}

The profound questions of philosophy are not supposed to be English questions. Historically that should be clear. The big questions of Anglophone philosophy are ones which can trace their discussion through ancient Greek, Latin, Arabic and many of the modern European languages. Moreover, these discussions have analogues in philosophical traditions from around the world, including various African, Indian and Chinese traditions. Questions about existence, human nature and freedom are simply not language-specific questions. So, approaching them solely through usage of English words in English corpora risks adopting an intrinsically chauvinist methodology.$^{17}$ Now, of course, this is mitigated a bit by the fact that we would never expect a philosopher to be using corpora as their sole resource. And there are probably some philosophers who would be happy restricting philosophical enquiry to the analysis of culturally specific ways of thinking and talking about such things. ${ }^{18}$ Nonetheless, for many philosophers, the worry will be there.

This worry is in some ways analogous to worries that many have raised about the demographic breakdown of participants in psychology experiments (Henrich et al. 2010a, 2010b). Similar worries extend to many studies in experimental philosophy. It is also analogous to certain worries that various people have raised about relying on intuitions in philosophy - where a contingent matter of fact relying on intuitions typically means relying on the intuitions of a very demographically homogeneous group. Given that the worry is analogous, one might expect the solution to be the same. In these other cases, the solution (or part of it) is typically to diversify your sample in some way.

In experimental philosophy and psychology, to make sure one has a diverse sample or to encourage cross-cultural studies and replication attempts. ${ }^{19}$ In traditional philosophy, one can take extra steps to encourage those from under-represented demographic groups into

\footnotetext{
${ }^{17}$ Worries in this vicinity seem less urgent and perhaps even irrelevant for corpus research, where the primary objective is to better understand something about language, a specific language or a specific culture.

${ }^{18}$ Although, even so-called 'ethno-philosophers' tend to place emphasis on using comparing and contrasting different ways of thinking (e.g. Maffie 2002).

${ }^{19}$ Stephen Stich and Edouard Machery have a project underway to help do just this - Intellectual Humility and Cultural Diversity in Philosophy: An Examination of the Extent and Implications of Cultural Diversity in Philosophical Intuition (see thethrivecenter.org/research/research-projects/the-science-of-intellectual-humility).
} 
the profession. ${ }^{20}$ In the case of corpus research, the analogous solution brings difficulties. How does one diversify the sample? The obvious way is to look at multiple languages. This brings obvious practical difficulties. But, more importantly, the problem of a non-diverse sample may already be embodied in the existing materials, for example, there are structural problems in how representative corpora are in the first place. For obvious reasons, corpora of English are much better established (even than other European languages, e.g. French) (Sharoff 2006). There might also be worries about the representation of the language-use of various groups within the corpora philosophers might use. Seildhofer (2012) notes the language compiled in BNC/COCA is effectively defined as "what has been produced by so-called educated and predominantly British and American (etc.) native speakers" (p.136). Auer et al. (2014) note "the upper layers of society and men are over-represented in diachronic corpora" (p.10). The underrepresentation of the language-use of women in corpora has been noted from the Early Modern period (Culpeper Kytö 2010, p.26), to internet corpora (Sharoff 2006, p.444).

Of course, there are sophisticated techniques available to help create corpora with better representation of, for example, female writers and to allow for cross-linguistic work. For instance, the use of web crawling (à la the WaCky initiative - Baroni et al. 2009) and the creation and use of parallel and comparable corpora (see McEnery and Xiao 2007). However, philosophers probably oughtn't to be expected to be able to jump in at the deep end. It seems likely that those interested in bringing corpus-based methods to philosophy will have to content themselves with more established, freely available and straightforward resources for the time being. In many cases, this will likely mean focusing on use of English. Nonetheless, making sure that their findings don't simply reflect quirks of English usage will be something such researchers will need to look out for. ${ }^{21}$

And, more generally, we must recognise that philosophy is not unique and will follow a well-trodden path. If we can derive value from the digital humanities, then it seems likely that we will have to continue to do so cautiously in the longer term.

The Gartner Hype Cycle...looks at how technologies are launched, mature, and are applied (so people know when to invest). The premise of this is that when technologies are first triggered, everyone thinks they are going to be the Next Big Thing, and so they reach 'the peak of inflated expectations', before

\footnotetext{
${ }^{20}$ Various projects are underway to help do this. For example, see Minorities and Philosophy (mapforthegap.com) and Gendered Conference Campaign (feministphilosophers.wordpress.com/gendered-conferencecampaign).

${ }^{21}$ Note again, that the metaphilosophical bent of Andow and Tallant's case studies means that they are (to some extent) isolated from such worries given the nature of the academic writings relevant to their research questions as their questions do concern specific communities.
} 
crashing down into a 'trough of disillusionment' when those adopting them realise they are not that great at all. It is hard work to get technologies up the 'slope of enlightenment' where useful, useable applications are found.

(Terras 2016: 1642-1643)

As we say, we assume that philosophy will be no different. It will be difficult to generate uptake of new methods and, if we can, this may well lead to an inflation of expectations a risk that all new technologies carry with them. Our development of these methods will thus need to be rigorous and cautious. Nonetheless, it is clear that philosophy is a discipline that has much to learn and much to benefit from when it come to the digital humanities.

Indeed, we want to move on with a note of optimism. The methodology that we are proposing, here, has promise. While there may be worries about focusing on English and the demographic representativeness of widely available corpora, it is important to note that, while imperfect, use of corpora is almost immediately an improvement on, for example, the standard philosophical practice of interrogating only one's own and other philosophers' ideas about 'what people would say'. Large and widely available corpora such as COCA and BNC incorporate usage from speech, fiction, popular magazines, newspapers, etc., and allow one to focus on particular types of use. This gives some traction into the question of how ideas and concepts are used a long way outside the academy. Similarly, one might think that access to corpora of web-based usage (e.g. UKWaC) and particularly social media (e.g. HERMES) would allow another insight into how language is used (in highly nonacademic contexts). These are exciting possibilities. If we can take advantage of them, then this will likely allow philosophers to explore language-use in ways which they have not been able to, to this point.

\section{Summary}

The potential for corpus-based research to contribute to philosophical enquiry is clear. Many ways of conceiving of philosophical enquiry make it amenable to empirical enquiry. However, the road to the use of such methods being accepted in philosophy won't be a smooth one. There are important issues to be addressed and metaphilosophical questions to be asked and answered. Just like experimental philosophy, corpus-based research in philosophy should be expected to encounter heated resistance and raise heated discussions about the nature of philosophical enquiry. If the fate of corpus-research in philosophy were to be anything like that of experimental philosophy, corpus research will probably at first contribute largely at the metaphilosophical level (raising challenges and spurring debate) and in putting philosophers' empirical claims to the test before becoming established as a field and developing clear research programmes of its own. 
We close on a rather different note. For many subjects, there is a philosophy of that subject: physics, chemistry, biology, psychology, mathematics, economics - the list goes on. What mainstream philosophy has not yet managed to produce is a substantial philosophy of the digital humanities (or of any of the sub-fields contained therein). Of course, that is not to say that these areas are devoid of philosophical interest or that no good philosophy is being done in those fields. We make no such claims. Indeed, tentatively, we think that there are areas where careful philosophical analysis may prove useful - though we wish to only suggest such a conclusion. One central question to which philosophy may be able to add something concerns the question of when a corpus is representative, and what it is representative of. Indeed, more generally, applied linguistics itself is a field that encompasses a considerable variety of approaches and stepping off points (see, e.g. Scholz et al. forthcoming). Making appropriate use of philosophical tools (conceptual analysis, for instance) may ultimately prove a useful way of making progress here. There are considerable bodies of work within the philosophical canon that explore what it is to represent something; what representation itself is. Deploying these notions may well be of use in the development and refinement of new corpus methods.

\section{Future reading}

1. Bluhm, R. (2016). Corpus Analysis in Philosophy In Martin Hinton (ed.), Evidence, Experiment and Argument in Linguistics and the Philosophy of Language. Peter Lang, pp. 91-109.

2. Caton, Jacob N. (2020). Using Linguistic Corpora as a Philosophical Tool. Metaphilosophy. 51(1): 51-70.

3. Scholz, Barbara C., Pelletier, Francis Jeffry and Pullum, Geoffrey K. (2016). Philosophy of Linguistics, The Stanford Encyclopedia of Philosophy (Winter 2016 Edition), Edward N. Zalta (ed.). Available here

\section{References}

Alfano, M. and Higgins, A. (2019). Natural language processing and semantic network visualization for philosophers. In E. Fischer and M. Curtis (eds.), Methodological advances in experimental philosophy. London: Bloomsbury.

Alfano, M., Higgins, A. and Levernier, J. (2018). Identifying virtues and values through obituary data-mining. The Journal of Value Inquiry 52(1): 59-79.

Andow, J. (2015a). How distinction is philosophers' intuition talk? Metaphilosophy 46(4-5): $515-538$. 
Andow, J. (2015b). How ‘intuition’ exploded. Metaphilosophy 46(2): 189-212.

Andow, J. (2016). Intuitions (a critical notice of Rowbottom and Booth. eds. Intuitions. OUP.). Analysis 76(2): 232-246.

Andow, J. (2017). Intuition-talk: Virtue or vice. Philosophia 45(2): 523-531.

Auer, A., Laitinen, M., Gordon, M. and Fairman, T. (2014). An electronic corpus of letters of artisans and the labouring poor (England, c. 1750-1835): Compilation principles and coding conventions. In V. Lieven, K. Davidse, C. Gentens and D. Kimps (eds.), Recent advances in corpus linguistics: Developing and exploiting corpora. Amsterdam and New York: Rodopi, pp. 7-29.

Baroni, M., Bernardini, S., Ferraresi, A. and Zanchetta, E. (2009). The WaCky wide web: A collection of very large linguistically processed web-crawled corpora. Language Resources and Evaluation 43(3): 209-226.

Beaney, M. (2015). Analysis. In E.N. Zalta (ed.), The Stanford encyclopedia of philosophy, Spring 2015 ed. Available here (Accessed 9 April 2019).

Buckwalter, W. (2012). Non-traditional factors in judgments about knowledge. Philosophy Compass 7(4): 278-289.

Cappelen, H. (2012). Philosophy without intuitions. Oxford: Oxford University Press.

Cappelen, H. (2014). X-Phi without intuitions? In A.R. Booth and D.P. Rowbottom (eds.), Intuitions. Oxford: Oxford University Press.

Culpeper, J. and Kytö, M. (2010). Early modern English dialogues: Spoken interaction as writing. Cambridge: Cambridge University Press.

Deutsch, M. (2010). Intuitions, counter-examples, and experimental philosophy. Review of Philosophy and Psychology 1(3): 447-460.

Deutsch, M. (2015). The myth of the intuitive: Experimental philosophy and philosophical method. London: MIT Press.

Goldman, A.I. (2007). Philosophical intuitions: Their target, their source, and their epistemic status. Grazer Philosophische Studien 74(1): 1-26.

Hansen, N. (2014). Contemporary ordinary language philosophy. Philosophy Compass 9(8): $556-569$.

Henrich, J., Heine, S.J. and Norenzayan, A. (2010a). Most people are not weird. Nature 466(7302): 29.

Henrich, J., Heine, S.J. and Norenzayan, A. (2010b). The weirdest people in the world? Behavioral and Brain Sciences 33(2-3): 61-83. 
Hintikka, J.(1999). The emperor's new intuitions. The Journal of Philosophy 96(3): 127-147. Jenkins, C. (2014). 'Intuition', intuitions, concepts and the A priori. In A. Booth and D. Rowbottom (eds.), Intuitions. Oxford: Oxford University Press.

Kauppinen, A. (2007). The rise and fall of experimental philosophy. Philosophical Explorations 10(2): 95-118.

Knobe, J. (2007). Experimental philosophy. Philosophy Compass 2(1): 81-92.

Knobe, J. (2016). Experimental philosophy is cognitive science. In J. Sytsma and W. Buckwalter (eds.), A companion to experimental philosophy. Oxford: Blackwell.

Knobe, J. and Nichols, S. (2008). An experimental philosophy manifesto. In J. Knobe and S. Nichols (eds.), Experimental philosophy, vol. 2. Oxford: Oxford University Press, pp. 3-14.

Ladyman, J. and Ross, D. (2007). Every thing must go. Oxford: Oxford University Press.

Laurence, S. and Margolis, E. (1999). Concepts and cognitive science. In S. Laurence and E. Margolis (eds.), Concepts: Core readings. London: MIT Press, pp. 3-81.

Machery, E. (2017). Philosophy with its proper bounds. Oxford: Oxford University Press.

Maffie, J.(2002). Why care about Nezahualcoyotl? Veritism and Nahua philosophy. Philosophy of the Social Sciences 32(1): 71-91.

Martinson, B.C., Anderson, M.S. and De Vries, R. (2005). Scientists behaving badly. Nature 435(7043): 737.

Marton, F., Fensham, P. and Chaiklin, S. (1994). A nobel's eye view of scientific intuition: Discussions with the nobel prize-winners in physics, chemistry and medicine (197086). International Journal of Science Education 16(4): 457-473.

McEnery, A. and Xiao, R. (2007). Parallel and comparable corpora: What is happening. Incorporating corpora. The Linguist and the Translator: 18-31.

Naess, A. (1938). 'Truth' as conceived by those who are not professional philosophers. Oslo: I Kommisjon Hos Jacob Dybward, pp. 12-15.

Nagel, J. (2013). Knowledge as a mental state. Oxford Studies in Epistemology 4: 275-310.

Nichols, S., Stich, S. and Weinberg, J.M. (2003). Metaskepticism: Meditations in ethnoepistemology. In S. Luper (ed.), The skeptics. Aldershot: Ashgate, pp. 227-247.

Pust, J. (2014). Intuition. In E.N. Zalta (ed.), The Stanford encyclopedia of philosophy, Fall ed. Available here (Accessed 9 April 2019).

Richard, M. (2015). Truth and truth bearers: Meaning in context, vol. 2. Oxford: Oxford University Press. 
Rosch, E. and Mervis, C. (1975). Family resemblances: Studies in the internal structure of categories. Cognitive Psychology 7: 573-605.

Rosenbloom, P. (2012). Towards a conceptual framework for the digital humanities. Digital Humanities Quarterly 6(2): 219-233.

Rysiew, P. (2011). Epistemic contextualism. In E.N. Zalta (ed.), The Stanford encyclopedia of philosophy, Winter 2011 ed. Available here (Accessed 9 April 2019).

Scholz, B.C., Pelletier, F.J. and Pullum, G.K. (2016). Philosophy of linguistics. In E.N. Zalta (ed.), The Stanford encyclopedia of philosophy, Winter 2016 ed. Available here (Accessed 9 April 2019).

Seildhofer, B. (2012). Corpora and English as a Lingua Franca. In K. Hyland, C. M. Huat and M. Handford (eds.), Corpus applications in applied linguistics. London: Bloomsbury.

Sharoff, S. (2006). Creating general-purpose corpora using automated search engine queries. In M. Baroni and S. Bernardini (eds.), Wacky! Working papers on the web as corpus. Bologna: Gedit, pp. 63-98.

Slingerland, E. (2013). Body and mind in early China: An integrated humanities - science approach. Journal of the American Academy of Religion 81(1): 6-55.

Slingerland, E. and Chudek, M. (2011). The prevalence of mind - body dualism in early China. Cognitive Science 35: 997-1007.

Slingerland, E., Nichols, N., Neilbo, K. and Logan, C. (2017). The distant reading of religious texts: A 'big data'approach to mind-body concepts in early China. Journal of the American Academy of Religion 85(4): 985-1016.

Stich, S. and Weinberg, J. (2001). Jackson's empirical assumptions. Philosophy and Phenomenological Research 62(3): 637-643.

Tallant, J. (2013). Intuitions in physics. Synthese 190: 2959-2980.

Tallant, J. (2015). Metaphysics, intuitions and physics. Ratio 28: 286-301.

Tallant, J. (Forthcoming). Critical review. Analysis.

Terras, M. (2016). A decade in digital humanities. Journal of Siberian Federal University: Humanities \& Social Sciences 7: 1637-1650.

Williamson, T. (2007). Philosophy of philosophy. Oxford: Blackwell. 